\title{
Body weight composition and physical fitness of 17-18-year- old agricultural university students with different motor activity amounts
}

\author{
Sergey Blinkov ${ }^{*}$, Sergey Levushkin ${ }^{2}$, Victor Kosikhin ${ }^{3}$ \\ ${ }^{1}$ Samara State Agrarian University, 446442, Samara, Russia \\ ${ }^{2}$ Institute of Developmental Physiology of the Russian Academy of Education, 119121, Moscow, Russia \\ ${ }^{3}$ Moscow State Linguistic University, 119034, Moscow, Russia
}

\begin{abstract}
The article presents the comparative analysis results of body weight composition and physical fitness of 17-18-year-old students who are engaged in sports and not engaged in sports. Students with a higher volume of physical activity have a higher content of active cell mass, water in the body (by $1.62 \%$ and $3.31 \%$, respectively), a lower body mass index, and the content of total and visceral fat (by $1.59 \%, 4.98 \%$ and $1.44 \%$, respectively). There is a high correlation with a higher level of physical fitness. For all seven motor tests that characterize the development of basic conditioning and coordination abilities, the indicators of athletes are higher. In general, $27.2 \%$ of female athletes have an above-average level of physical fitness, the average level was found in $54.45 \%$ and below the average in $18.18 \%$. It is significantly higher than the same indicators for non-sports students.
\end{abstract}

\section{Introduction}

One of the most important areas of higher education is to preserve and strengthen the health of students. Implementation of this direction is carried out in the developing process the humanities profile of "Physical culture and sport" and "Elective courses for physical culture and sport", in the system of self-study students, and sectional shape of the improving sports skills process. Many students suffer from various chronic diseases or they are obese. The main reason for this a low level of physical activity. It results in a low level of physical fitness [1-7, 9, 11, 13]. Optimal physical activity positively affects the composition of body weight according to the physiological principle "work builds an organ". People who regularly engage in physical exercise increase the percentage of active cell mass. The fat component of the body mass composition decreases, that is, the passive cell mass decreases. Today, in scientific research and in household use, the body mass index indicator is used. It is one of the main components of human somatic health. The upper limit of the norm of the body mass index is $25 \mathrm{~kg} / \mathrm{m} 2$, after which pre-obesity begins.

To assess the level of physical health, specialists use proven and generally accepted methods for assessing morphofunctional development. They also use the popular bioimpedance method for analyzing the body weight composition. This method helps to obtain information about the ratio of muscle, fat, and total cell mass, total body fluid, and other parameters based on the biological values of the electrical impedance of various human body structures [12].

The problem of optimizing physical activity in terms of increasing the active cell mass indicators and normalizing the body mass index becomes increasingly important. The research related to the qualitative change in the composition of body weight under the influence of exercise becomes more and more relevant.

\section{Materials and Methods}

The purpose of this study was to conduct a comparative analysis of bioimpedance analysis indicators and physical fitness of 17-18 years female students of Samara State University who are engaged in sports and not engaged in sports. Athletes who participated in the experiment were engaged in such sports as volleyball, athletics and powerlifting. All of them had mass sports categories. The volume of motor activity of female students not engaged in sports did not exceed 3 hours per week. Female students-athletes engaged in physical exercises within the optimal volume of motor activity for this age group trained 8-10 hours per week.

The objectives of our research included: 1) Study of the body mass composition of female athletes and nonathletes aged 17-18 years; 2) testing of motor fitness; 3) conducting a comparative analysis of bioimpedance indicators and physical fitness of female and non-female athletes. The study involved 79 female students aged 17-18 years. The method of R. N. Dorokhov was used [8]. During the study, we measured the length and weight of the

\footnotetext{
*Corresponding author: blinkovsn@mail.ru
} 
body, body mass index (BMI), the content of muscle and fat components, visceral fat, total fluid and basal metabolism of female students. Seven motor tests were used to assess the level of general physical fitness (GPA). Namely, running 100 meters, shuttle run 3x10 meters, long jump from a place, lifting the torso, hands behind the head for 1 minute, push-ups from the floor (girls) and pull-ups on a high crossbar (boys), running 1000 meters, forward tilt from a standing position on a gymnastic bench. These motor tests allowed us to assess the level of highspeed motor qualities development, coordination abilities, speed-strength, strength physical qualities, endurance and flexibility.

The statistical processing of the obtained results was performed. For data with a normal distribution, the mean (M) and for the error the mean (m) were calculated. When comparing sample averages for data with a normal distribution, the Student's criterion is used. For all types of analysis, $\mathrm{p}<0.05$ was considered statistically significant. To speed up the process of research results statistics, we used a computer program for monitoring and correcting the physical development and students physical fitness, proposed by S. P. Levushkin [10].

\section{Results and Discussion}

There are no any significant differences between the female athletes groups and non-athletes in terms of body length and weight. However, we found significant differences in the values of body weight and BMI $(p<0.01 ; p<0.05)$. In terms of general and visceral body fat of the subjects it was revealed that the values of this index is significantly $(\mathrm{p}<0.01)$ more girls' non-athletes in comparison with the same values of athletes $(15,19 \%$ and $10,21 \%$; of $5.44 \%$ and $4.0 \%$, respectively) (table. 1). The active cell mass (ACM), a comparative analysis showed that the value of this indicator in athletes is significantly $(\mathrm{p}<0.05)$ higher than in similar indicators of non-athletes by $1.72 \%$. The indicator of total body fluid, which indirectly indicates a higher percentage of muscle mass (as a component of $\mathrm{ACM})$ in female athletes is significantly $(\mathrm{p}<0.05)$ higher by $3.31 \%$ compared to girls who do not regularly engage in physical culture and sports (table 1).

Table 1. Body weight composition indicators of female students aged 17-18 years of Samara agricultural University, who have different physical activity amounts.

\begin{tabular}{|l|c|c|c|}
\hline \multicolumn{1}{|c|}{ Parameters } & Non-athlètes & Athlètes & $\begin{array}{c}\text { The significance of } \\
\text { differences }\end{array}$ \\
\hline Height, cm & $164,81 \pm 1,35$ & $165,1 \pm 1,26$ & - \\
\hline Weight, kg & $59,51 \pm 1,84$ & $55,38 \pm 1,23$ & $* *$ \\
\hline BWI, \% & $21,95 \pm 0,38$ & $20,36 \pm 0,45$ & $* *$ \\
\hline Total fat, \% & $15,19 \pm 1,5$ & $10,21 \pm 1,1$ & $*$ \\
\hline ACM, kg & $48,55 \pm 1,1$ & $46,07 \pm 0,83$ & $*$ \\
\hline ACM, \% & $81,58 \pm 0,88$ & $83,2 \pm 0,73$ & - \\
\hline Total fluid, \% & $59,59 \pm 0,94$ & $62,9 \pm 1,26$ & $*$ \\
\hline Visceral fat, \% & $5,44 \pm 0,47$ & $4,0 \pm 0,38$ & $*$ \\
\hline $\begin{array}{l}\text { The basal metabolic } \\
\text { rate, kcal }\end{array}$ & $1410,0 \pm 32,3$ & $1398,36 \pm 27,07$ & $*$ \\
\hline Note: $*$ reliable at $\mathrm{p}<0.05 ; *$ - reliable at $\mathrm{p}<0.01$ & & $*$ \\
\hline
\end{tabular}

Along with the body mass composition assessment, we try to conduct a comparative analysis of the physical fitness level of students with different motor activity amounts. The indicator of speed abilities development, estimated by us according to the results in the 100-meter run, among students who have a higher level of physical activity compared to girls who are not athletes, is significantly $(\mathrm{p}<0.01)$ higher. Female athletes run 100 meters on average 1.3 seconds faster (table 2). the situation is similar in the development of coordination abilities. The result in the $3 \times 10$-meter shuttle race was significantly $(\mathrm{p}<0.01)$ higher (by 1.21 seconds) compared to non-athletes (table 2$)$. The level of speed and strength abilities development in athletes was also significantly $(\mathrm{p}<0.01)$ higher compared to nonathletes. This is confirmed by the length of the long jump from the place where the athletes ' result is higher by $27.33 \mathrm{~cm}$ (table 2). The number of torso lifting for 1 minute from the supine position, characterizing the level of power endurance development of female students involved in sports significantly $(\mathrm{p}<0.01)$ higher at 9.61 lifting (table. 2). The power endurance development level of arms extensors muscles, measured by the number of push-ups in girls with higher physical activity level significantly $(\mathrm{p}<0.05)$ higher (by 2.61 pushups) compared with nonathletes (table. 2). Comparative analysis showed that the flexibility of the vertebral column in female athletes was significantly higher $(\mathrm{p}<0.05)$ compared to non-athletes. This fact is confirmed by the indicator in the forward tilt from the standing position on the gymnastic bench. In female athletes, the slope value is greater (by $2.88 \mathrm{~cm})$ compared to the group of non-athletes (table 2). Finally, a comparative analysis of the general endurance development, determined by the results of the 1000-meter run of female and non-female athletes, showed that female athletes have a significantly $(\mathrm{p}<0.01)$ higher indicator. The time to overcome the test distance was 309.4 seconds, which is 78.1 seconds less than for non-athletes (table 2).

Table 2. Physical fitness tests of female students aged 17-18 years of Samara Agricultural University, who have different amounts of physical activity 


\begin{tabular}{|l|c|c|c|}
\hline \multicolumn{1}{|c|}{ Paramétrés } & Non-athletes & Athletes & $\begin{array}{c}\text { The significance of } \\
\text { differences }\end{array}$ \\
\hline Running 100 m, sec. & $18,23 \pm 0,27$ & $16,93 \pm 0,32$ & $* *$ \\
\hline Running 1000 m, sec. & $387,5 \pm 6,1$ & $309,4 \pm 7,06$ & $* *$ \\
\hline Shuttle run 3x10 m, sec. & $9,38 \pm 0,1$ & $8,17 \pm 0,08$ & $* *$ \\
\hline Long jump from a standstill, cm & $164,3 \pm 3,59$ & $191,63 \pm 5,99$ & $* *$ \\
\hline $\begin{array}{l}\text { Leaning forward from a standing } \\
\text { position on a gymnastic bench, cm }\end{array}$ & $12,85 \pm 1,27$ & $15,73 \pm 1,68$ & $*$ \\
\hline $\begin{array}{l}\text { Lifting the torso, hands behind the } \\
\text { head for 1 minute, number of times }\end{array}$ & $30,89 \pm 1,45$ & $40,5 \pm 2,13$ & $*$ \\
\hline $\begin{array}{l}\text { Push-ups from the floor, number of } \\
\text { times }\end{array}$ & $11,75 \pm 1,43$ & $14,36 \pm 1,39$ & $*$ \\
\hline Note: * - reliable at p<0.05; * - reliable at p<0.01 & & $*$ \\
\hline
\end{tabular}

At the same time, the level of general physical fitness (GPA) of female athletes is also higher compared to nonfemale students. Thus, $27.27 \%$ of female athletes have an above-average level of GPA, while $54.55 \%$ of subjects have an average level of GPA in the same group, and $18.18 \%$ have a lower-than-average level of GPA. We do not identify a high level of GPA among female athletes. If we consider the level of GPA of female students who are not involved in sports, it is significantly lower compared to female athletes. Thus, only $34.85 \%$ of non-athletes have an average level of GPA, $51.18 \%$ of subjects have a lower average level of GPA, and $13.97 \%$ have a low level of GPA. We did not find a higher than average or high level of GPA among non-athletes.

\section{Conclusions}

Female students-athletes aged 17-18 years have significantly $(\mathrm{p}<0.01 ; 0.05)$ higher content of ACM, total body fluid ( $1.62 \%$ and $3.31 \%$, respectively), lower body mass index, total and visceral fat $(1.59 \%, 4.98 \%$ and $1.44 \%$, respectively) compared to non-athletes.

For all seven motor tests that characterize the development of basic conditioning and coordination abilities, the indicators of female students-athletes are reliable $(\mathrm{p}<0.05 ; 0.01)$ higher. They also have a higher rate of GPA. Thus, the above-average level of GPA among female athletes is $27.2 \%$, the average level of GPA is $54.45 \%$, and belowaverage- $18.18 \%$, which is significantly higher than similar indicators for female students who are not involved in sports.

Girls who are not athletes should optimize their motor activity and engage in more physical exercises. They should affect the level of GPA and a qualitative, positive change in body weight composition. Female students who are engaged in sports should maintain the level of GPA at the achieved level and pay more attention to the development of general endurance.

\section{References}

1. L.B. Andryushchenko, S.I. Filimonova, Theory and practice of physical culture, 2, 73-76 (2018)

2. G.L. Apanasenko, Yu.S. Chistyakova, Theory and practice of physical culture, 1, 19-22 (2006)

3. G.L. Apanasenko, Human Physiology, 1(36), 67-73 (2010)

4. G.L. Apanasenko, R.G. Naumenko, Theory and practice of physical culture, 6, 31 (2012)

5. S.N. Blinkov, Physical culture: education, education, training, 6, 60-62 (2015)

6. S.N. Blinkov, S.P. Levushkin, A.A. Krylova, M.M. Merdeev, Human ecology, 52, 13-14 (2006)

7. V.P. Golomolzina, A.V. Meshcheryakov, S.P. Levushkin, Human ecology, 1, 70 (2008)

8. A.S. Kuznetsov, Z.M. Kuznetsova, Russian Journal of Physical Education and Sport, 14(4), 5-7 (2019). DOI: 10.14526/20704798-2019-14-4-5-7

9. V.R. Kuchma, Russian pediatric journal, 1(21), 31-37 (2018)

10. S.P. Levushkin, O.F. Zhukov, S.N. Blinkov, F.M. Kodolova, Human ecology, 1, 65-66 (2006)

11. S.P. Levushkin, V.A. Khamzina, S.N. Blinkov, Research of the physical condition of students: monograph (USTU, Ulyanovsk, 2013)

12. M.V. Peshkov, E.P. Sharaykina, V.E. Bezoschnov, Modern problems of science and education, 6 (2014). URL: http://www.science-education.ru/ru/article/view?id=16682

13. T.N. Shutova, L.B. Andryushchenko, Theory and practice of physical culture, 3, 54-56 (2017) 